\title{
EFEITOS DOS MÉTODOS DE ABATE E SEXO NA COMPOSIÇÃO CENTESIMAL, PERFIL DE ÁCIDOS GRAXOS E COLESTEROL DA CARNE DE CAPIVARAS ${ }^{1}$
}

\author{
Sandra H. I. ODA², Maria C. BRESSAN ${ }^{2, *}$, Maria das G. CARDOSO ${ }^{3}$, Rilke Tadeu Fonseca de FREITAS ${ }^{3}$, \\ Giulianna Z. MIGUEL ${ }^{2}$, Peter B. FARIA ${ }^{3}$, Josye O. VIEIRA ${ }^{3}$, Ana Carolina C. PISA ${ }^{3}$, Taciana V. SAVIAN ${ }^{3}$
}

\section{RESUMO}

O objetivo desse trabalho foi avaliar os efeitos de métodos de abate (MA) (humanitário (MH) e por tiro (MT)) e sexo na composição centesimal, perfil de ácidos graxos (AG) e colesterol da carne de capivara (Hydrochaeris hydrochaeris L. 1766). Foram abatidos 20 animais (13 machos (M) e 7 fêmeas (F)) com peso médio de 45,71kg. No músculo longissimus dorsi (LD) foram determinados: umidade, lipídios totais (LT), proteina e cinzas e no semimembranosus (SM), o colesterol por colorimetria e o perfil de AG por cromatografia gasosa. O LD apresentou: $75,87 \%$ de umidade, $1,37 \%$ de LT, $22,11 \%$ de proteínas e $1,09 \%$ de cinzas. Houve diferença $(\mathrm{p}<0,01)$ nos teores de LT de M (1,75\%) e F $(0,98 \%)$. Os fatores sexo e MA não influenciaram: umidade, proteína e cinzas. Os AG encontrados em maior proporção

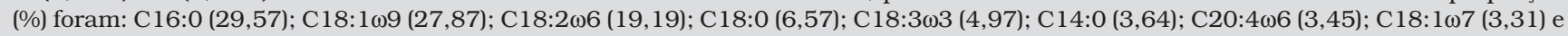
C16:1 $17(1,90)$. A relação AG poliinsaturados/saturados foi 0,82. As médias de AG $\omega 6$ e $\omega 3$ foram 23,41 e 5,63\%. Os fatores sexo e MA não influenciaram os poliinsaturados e colesterol $(28,11 \mathrm{mg} / 100 \mathrm{~g})$. A carne de capivara apresentou teores elevados de proteína e valores reduzidos de lipídios totais e de colesterol e relação $\omega 6 / \omega 3$ nutricionalmente adequada.

Palavras-chave: carne de capivara; composição centesimal; ácidos graxos; ácidos graxos poliinsaturados; colesterol; métodos de abate; sexo.

\section{SUMMARY}

EFFECT OF TWO SLAUGHTER METHODS AND SEX ON PROXIMATE COMPOSITION, CHOLESTEROL CONTENT AND FATTY ACIDS PROFILE OF CAPYBARA MEAT (Hydrochaeris Hydrochaeris L. 1766). The objective of this work was to evaluate the effects of two slaughter methods: traditional (TS) and head-shot (HS) and sex on the proximate composition, fatty acids (FA) profile and cholesterol content of capybara meat. Twenty animals (13 males (M) and 7 females (F)), weighting about $45.71 \mathrm{~kg}$, were slaughtered. In longissimus dorsi (LD) muscle were determined: moisture, crude fat, protein and ash. In semimembranosus (SM) muscle, were determined: cholesterol content for colorimetric method and fatty acids (FA) profile for gas chromatography. The LD muscle had values of: $75.87 \%$ of moisture, $1.37 \%$ of crude fat, $22.11 \%$ of crude protein, $1.09 \%$ of ash. There were significant differences $(\mathrm{p}<0.01)$ between lipid contents of $\mathrm{M}$

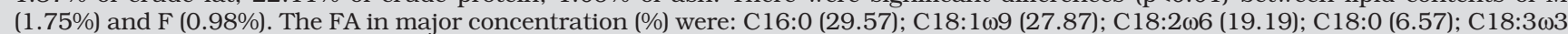

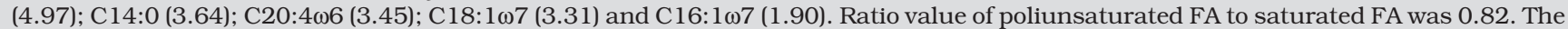
average values of $\omega 6 \mathrm{FA}$ and $\omega 3 \mathrm{FA}$ were 23.41 and $5.63 \%$, respectively. The factors sex and slaughter method had no effect on poliunsaturated FA percentages and cholesterol content $(28.11 \mathrm{mg} / 100 \mathrm{~g})$. Capybara meat presented low total lipid content and high crude protein values and FA $\omega 6 / \omega 3$ ratio considered nutritionally adequated.

Keywords: capybara meat; proximate composition; fatty acids; poliunsaturated fatty acids; cholesterol; slaughter methods; sex.

\section{1 - INTRODUÇÃO}

A carne é considerada um alimento nobre para o homem pela qualidade de proteínas, pela presença de ácidos graxos (AG) essenciais e de vitaminas do complexo B [27]. Entretanto, parte dos consumidores associa o consumo da carne vermelha à ocorrência de doenças cardiovasculares. Esses consumidores buscam, através da mudança de hábitos, combater o estresse, o sedentarismo e a nutrição desbalanceada típicos do estilo de vida do homem moderno, que contribuem para o aparecimento da obesidade, hipercolesterolemia e doenças cardiocirculatórias.

Em geral, carnes de animais silvestres [13, 18, 20, $25,34]$ apresentam proporção alta de AG poliinsaturados e teores reduzidos de lipídios totais [37]. A exploração racional de animais silvestres é uma ferramenta na conservação da biodiversidade capaz de transformar os animais silvestres em fontes renováveis de produtos de grande rentabilidade. Entre as propostas de uti-

1. Recebido para publicação em 01/08/2002. Aceito para publicação em 20/04/2004 (000926).

2. Departamento de Ciências dos Alimentos - Universidade Federal de Lavras/UFLA. Caixa Postal 37, CEP 37200-000, Lavras-MG

3. Alunos de graduação da UFLA.

* A quem a correspondência deve ser enviada. lização racional dos recursos de fauna estão: a criação dos animais em cativeiro, a implantação de fazendas de caça esportiva (Agenda 21), entre outras. Embora a demanda pela carne de animais silvestres seja elevada, a oferta é baixa e instável. Um fator limitante na comercialização da carne de capivaras é a falta de estudos das características de qualidade.

O presente estudo teve por objetivo caracterizar a composição química da carne de capivaras submetidas a duas modalidades de abate.

\section{2 - MATERIAL E MÉTODOS}

\section{1 - Material}

Foram utilizadas 20 capivaras (13 machos e 7 fêmeas), com peso médio de $45,71 \mathrm{~kg}$, provenientes de um zoocriadouro, abatidas em julho de 2001, sob inspeção federal. As amostras foram cedidas pela empresa Pró-Fauna (IBAMA, no 1-35-93-0848-0), com sede em Iguape (SP).

\section{2 - Tratamentos}

No desembarque, os animais foram divididos aleatoriamente em 2 grupos de 10 animais e cumpriram 
tempo de descanso de $24 \mathrm{~h}$ em baias coletivas. No primeiro tratamento, o lote foi submetido ao abate humanitário $(\mathrm{MH})$, em que os animais foram insensibilizados (300V, 2A por 5s) e sangrados após 15 segundos. No segundo tratamento, os animais foram submetidos ao método de abate por tiro (MT) na região temporo-ocipital e, após 10 minutos, foram conduzidos ao abatedouro. A partir dessas operações, os animais do tratamento por método de abate convencional e tiro foram sangrados, escaldados $\left(60^{\circ} \mathrm{C}\right)$, depilados, eviscerados, inspecionados, serrados longitudinalmente e resfriados.

\section{3 - Coleta de amostras}

As amostras para a composição centesimal foram retiradas do músculo longissimus dorsi (LD) (porção cranial do corte denominado "carré”) e para as análises de perfil de AG e colesterol, do músculo semimembranosus (SM) das meias-carcaças esquerda e direita. Depois de embaladas em papel alumínio e identificadas, as amostras foram acondicionadas em sacos plásticos e congeladas a $-12^{\circ} \mathrm{C}$ até a realização das análises. Para as análises, as amostras foram descongeladas a $3,5 \pm 0,5^{\circ} \mathrm{C}$.

\section{4 - Análises laboratoriais}

\subsection{1 - Composição centesimal}

Para a determinação da composição centesimal, as amostras foram homogeneizadas em multiprocessador até a obtenção de uma massa homogênea. A proteína bruta foi quantificada pelo método de Kjeldahl, os lipídios totais (LT) foram extraídos pelo método de Soxhlet, a umidade em estufa a $105^{\circ} \mathrm{C}$ até a obtenção de peso constante, e as cinzas em mufla a $550^{\circ} \mathrm{C}$ [1]. As análises foram realizadas em triplicata.

\subsection{2 - Perfil de ácidos graxos (AG) e teor de colesterol}

Para a realização das análises de colesterol e perfil de AG, os lipídios foram extraídos, conforme metodologia de FOLCH, LESS \& SLOANE-STANLEY [12], adaptada para amostras de 5 gramas, que foi homogeneizada em 50mL de clorofórmio/metanol (2:1). A amostra homogeneizada foi filtrada para funil de separação de $250 \mathrm{~mL}$, permanecendo em repouso por 2 horas para a separação física. A fração apolar do homogeneizado, contendo lipídios e clorofórmio, foi recolhida e a fração polar foi descartada. A fração apolar foi submetida à nova separação por 12 horas e, dessa segunda separação, a fração apolar foi recolhida em balão volumétrico e foi adicionado clorofórmio até completar 50mL. Desse extrato foram retirados $5 \mathrm{~mL}$ para a determinação de colesterol e $5 \mathrm{~mL}$ para a determinação do perfil de ácidos graxos.

A determinação de colesterol foi realizada por colorimetria, segundo BOHAC et al. [2], adaptado por BRAGAGNOLO \& RODRIGUEZ-AMAYA [5], em que a alíquota de $5 \mathrm{~mL}$ foi evaporada com nitrogênio gasoso e submetido a saponificação com solução de hidróxido de potássio em etanol 12\%. A fração insaponificável (coles- terol) foi extraída com hexano, purificada e submetida a reação de cor com ácido acético e ácido sulfúrico, tendo como catalisador o sulfato ferroso. Em seguida, foi procedida a leitura em espectrofotômetro a 490nm. A curva de calibração para colesterol foi elaborada utilizando-se 0,01 gramas de colesterol p.a., diluído em 50mL de hexano, do qual foram retiradas alíquotas que corresponderam a 40, 80, 120, 160 e 200mg/mL. Essa curva foi linear passou pela origem e cobriu a faixa de concentração das amostras.

Para a determinação dos diferentes ácidos graxos, as amostras foram inicialmente saponificadas com hidróxido de sódio com metanol 0,5M e metiladas com solução de cloreto de amônia, metanol e ácido sulfúrico, segundo metodologia de HARTMAN \& LAGO [17]. Após a metilação, $5 \mathrm{~mL}$ de hexano foi adicionado a amostra e submetidos à agitação por 10 segundos. Do sobrenadante foi retirada uma alíquota de $3 \mathrm{~mL}$ que foi concentrada com nitrogênio gasoso, ressuspendida em 100mL de hexano e para a injeção foi tomada uma alíquota de $1 \mathrm{~mL}$.

As amostras foram submetidas à cromatografia gasosa e injetadas manualmente em cromatógrafo a gás (marca Shimadzu, modelo GC-17A), equipado com detector de ionização de chama, injetor split na razão de 1:5, coluna capilar de polietileno-glicol DB-Wax $(30 \mathrm{~m}$; $0,25 \mathrm{~mm} ; 0,25 \mu \mathrm{m})$ e acoplado a um software, desenvolvido pela Shimadzu. As condições cromatográficas foram: temperatura inicial da coluna: $180^{\circ} \mathrm{C}$ por $10 \mathrm{minu}-$ tos, aumentada a uma taxa de $5^{\circ} \mathrm{C} /$ minutos até a temperatura final da coluna de $240^{\circ} \mathrm{C}$, permanecendo nessa temperatura por 18 minutos; temperatura do injetor: $230^{\circ} \mathrm{C}$; e temperatura do detector: $250^{\circ} \mathrm{C}$. O gás de arraste utilizado foi o nitrogênio em fluxo de $01 \mathrm{~mL} /$ minuto.

Os diferentes ácidos graxos foram identificados por comparação aos tempos de retenção apresentados pelo padrão cromatográfico (Pufa 2, Sigma-Aldrich), constituído por uma mistura de 14 ácidos graxos. A quantificação dos ácidos graxos foi realizada por normalização.

\section{5 - Delineamento experimental e análise estatís- tica}

O delineamento experimental utilizado foi o inteiramente casualizado (DIC), numa estrutura em fatorial 2 × 2 (2 métodos de abate e 2 sexos), em que cada capivara foi considerada uma unidade experimental. Os resultados foram analisados pelo SAS EUA, Cary [35].

O modelo experimental para as análises de composição centesimal (umidade, proteína, lipídios totais e cinzas), teor de colesterol e perfil de AG (os 14 ácidos graxos determinados), foi:

$$
Y i j=\mu+M i+S j+(M S) i j+P+E i j .
$$

onde:

Yij = observação no músculo LD de capivaras abatidas pelo método i, do sexo j;

$\mu=$ média geral do experimento; 
$\mathrm{Mi}=$ efeito do método de abate $\mathrm{i}$, sendo $\mathrm{i}=1,2$;

$\mathrm{Sj}=$ efeito do sexo $\mathrm{j}$, sendo $\mathrm{j}=1,2$;

(MS)ij = efeito da interação do método de abate i com o sexo $\mathrm{j}$;

$\mathrm{P}=$ covariável de peso ao abate;

Eij = erro experimental associado à observação Yij, normalmente distribuída, com média 0 e variância $\sigma^{2}$.

Com relação aos resultados da análise estatística, quando a análise de variância não determinou diferença significativa para a interação entre os fatores (método de abate e sexo), a análise foi direcionada para os fatores principais e quando a análise de variância determinou diferença significativa nos fatores, os dados foram submetidos ao teste- $t$ (Student).

\section{3 - RESULTADOS E DISCUSSÃO}

\section{1 - Composição centesimal}

Não foram encontradas diferenças significativas nos percentuais de umidade, proteína, cinzas e na composição de colesterol do músculo LD de capivaras para os fatores sexo e método de abate (Tabela 1). A interação entre os fatores sobre todos os parâmetros estudados também não foi significativa.

TABELA 1. Médias e erros-padrão da média (EP) da umidade, proteína, LT, cinzas e colesterol do músculo LD

\begin{tabular}{ccccc}
\hline & \multicolumn{2}{c}{ Sexo } & \multicolumn{2}{c}{ Método de Abate } \\
\cline { 2 - 5 } & Macho \pm EP & Fêmea \pm EP & Humanitário \pm EP & Tiro \pm EP \\
\hline Umidade (\%) & $75,57^{\mathrm{a}} \pm 0,20$ & $76,17^{\mathrm{a}} \pm 0,27$ & $75,93^{\mathrm{a}} \pm 0,25$ & $75,81^{\mathrm{a}} \pm 0,29$ \\
Proteína (\%) & $21,95^{\mathrm{a}} \pm 0,60$ & $22,26^{\mathrm{a}} \pm 0,50$ & $22,63^{\mathrm{a}} \pm 0,45$ & $21,58^{\mathrm{a}} \pm 0,43$ \\
Lipídios Totais (\%) & $1,75^{\mathrm{a}} \pm 0,15$ & $0,98^{\mathrm{b}} \pm 0,19$ & $1,57^{\mathrm{a}} \pm 0,17$ & $1,16^{\mathrm{a}} \pm 0,16$ \\
Cinzas (\%) & $1,05^{\mathrm{a}} \pm 0,02$ & $1,12^{\mathrm{a}} \pm 0,03$ & $1,05^{\mathrm{a}} \pm 0,03$ & $1,12^{\mathrm{a}} \pm 0,03$ \\
Colesterol (mg/100g) & $26,99^{\mathrm{a}} \pm 2,92$ & $29,21^{\mathrm{a}} \pm 4,01$ & $26,97^{\mathrm{a}} \pm 3,64$ & $29,23^{\mathrm{a}} \pm 3,42$
\end{tabular}

Médias seguidas da mesma letra são estatisticamente iguais entre si pelo teste- $t$ (Student) ao nivel de $5 \%$ de probabilidade $(\mathrm{p}<0,05)$, (nas linhas, letras minúsculas são para diferenciar os fatores sexo e método de abate).

Os valores de umidade variaram de 75,37 a 76,44\%. Em lombo, copa e paleta de capivaras são descritos valores de 75,09 a 77,29\% [19, 22, 30, 33]. Os teores de proteína variaram de 21,15 a 23,08\%. Esses resultados foram superiores aos valores relatados em pernil e paleta $(20,49 \%)$; copa $(20,04 \%)$ e lombo $(21,03-$ $22,10 \%)[14,19,22,30,33]$. Em carnes de animais selvagens, são descritos valores de proteína de 20,27 a $22,80 \%$ em zebras, oryx, kongoni, javalis, cervídeos e camelos [7, 21, 25, 39], enquanto em espécies domésticas, como bovinos, perus e frangos, são reportados teores variando de 17,54 a $20,4 \%$ [24, 26]. Os dados de literatura mostram que em animais de caça os valores de proteína são mais elevados do que em animais domésticos.

Não foram encontradas diferenças nos LT para os MA. Entretanto, houve diferença $(\mathrm{p}<0,01)$ entre os valores de LT de M (1,75\%) e F (0,98\%). Esses dados dis- cordam dos resultados de JARDIM [19] e SALDANHA [33] que citam que as fêmeas a partir da puberdade apresentam maior aptidão para acumular lipídios do que os machos. No presente trabalho, foi observado que entre os animais abatidos encontravam-se algumas fêmeas prenhas e, como na gestação o organismo materno passa por adaptações no metabolismo dos tecidos, a fim de garantir o suprimento de nutrientes ao feto (processo homeorético), provavelmente a gestação tenha sido responsável por essa menor porcentagem de lipídios nas fêmeas [8]. As médias de LT variaram de 0,79 a $1,90 \%$. Valores entre 0,20 a $2,50 \%$ foram relatados em zebra, oryx, kongoni, cervídeos e javali [21, 25, 39]. Por outro lado, em espécies domésticas, foram citados valores de 3,80 a $6,49 \%$ em perus, bovinos, ovinos e frangos [23, 24, 26].

Os teores de cinzas foram de 1,02-1,15\%. Em pernil, paleta, lombo e copa de capivaras, são reportadas médias de 0,90 a $1,18 \%[19,30,33]$. Os valores citados para caças como: oryx $(1,10 \%)$; kongoni $(1,20 \%)$; jacaré-do-Pantanal $(1,10 \%)$; cervídeos $(1,03-1,11 \%)$ e javalis $(1,03-1,11 \%)$ foram semelhantes aos encontrados nesse estudo, com exceção da zebra (1,50\%) [21, 25, 32, 39]. Em espécies domésticas, são relatados valores de 0,92 a $1,20 \%$ em bovinos, perus, ovinos e frangos [23, 24, 26].

\section{2 - Perfil de ácidos graxos (AG)}

TABELA 2. Médias e erros-padrão da média (EP) das porcentagens das áreas de pico dos AG do músculo SM

\begin{tabular}{|c|c|c|c|c|}
\hline \multirow{2}{*}{ Ácido graxo } & \multicolumn{2}{|c|}{ Método de abate } & \multicolumn{2}{|c|}{ Sexo } \\
\hline & Humanitário $\pm \mathrm{EP}$ & Tiro $\pm E P$ & Macho $\pm \mathrm{EP}$ & Fêmea $\pm \mathrm{EP}$ \\
\hline Mirístico (C14:0) & $3,33^{\mathrm{a}} \pm 0,27$ & $3,95^{a} \pm 0,37$ & $3,93^{\mathrm{a}} \pm 0,33$ & $3,35^{\mathrm{a}} \pm 0,31$ \\
\hline Palmítico (C16:0) & $27,34^{\mathrm{b}} \pm 0,94$ & $31,80^{a} \pm 1,29$ & $29,78^{a} \pm 1,17$ & $29,35^{a} \pm 1,10$ \\
\hline Esteárico (C18:0) & $7,33^{\mathrm{a}} \pm 0,34$ & $5,80^{\mathrm{b}} \pm 0,46$ & $5,60^{a} \pm 0,42$ & $7,53^{a} \pm 0,39$ \\
\hline 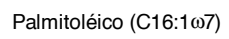 & $1,76^{a} \pm 0,30$ & $2,02^{a} \pm 0,41$ & $2,54^{\mathrm{a}} \pm 0,37$ & $1,24^{\mathrm{b}} \pm 0,35$ \\
\hline 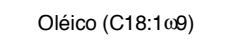 & $26,65^{\mathrm{a}} \pm 1,27$ & $27,13^{\mathrm{a}} \pm 1,74$ & $28,05^{a} \pm 1,58$ & $25,73^{\mathrm{a}} \pm 1,49$ \\
\hline Eicosenóico $(\mathrm{C} 20: 1 \omega 9)$ & $0,28^{\mathrm{a}} \pm 0,09$ & $0,17^{\mathrm{a}} \pm 0,12$ & $0,24^{\mathrm{a}} \pm 0,11$ & $0,20^{\mathrm{a}} \pm 0,10$ \\
\hline $\mathrm{C} 18: 1 \omega 7$ & $2,65^{a} \pm 0,48$ & $3,95^{a} \pm 0,66$ & $3,78^{a} \pm 0,60$ & $2,82^{a} \pm 0,57$ \\
\hline 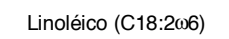 & $21,34^{a} \pm 1,23$ & $17,04^{a} \pm 1,69$ & $18,97^{\mathrm{a}} \pm 1,53$ & $19,41^{a} \pm 1,44$ \\
\hline 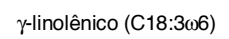 & $0,18^{a} \pm 0,01$ & $0,17^{\mathrm{a}} \pm 0,01$ & $0,18^{\mathrm{a}} \pm 0,01$ & $0,17^{\mathrm{a}} \pm 0,01$ \\
\hline$\alpha$-linolênico $(C 18: 3 \omega 3)$ & $5,04^{\mathrm{a}} \pm 0,37$ & $4,89^{a} \pm 0,55$ & $5,06^{a} \pm 0,47$ & $4,87^{\mathrm{a}} \pm 0,49$ \\
\hline 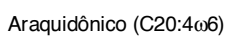 & $3,44^{a} \pm 0,68$ & $3,45^{a} \pm 1,01$ & $3,00^{\mathrm{a}} \pm 0,85$ & $3,89^{a} \pm 0,89$ \\
\hline AG (EPA) $(C 20: 5 \omega 3)$ & $0,51^{\mathrm{a}} \pm 0,10$ & $0,45^{\mathrm{a}} \pm 0,14$ & $0,45^{\mathrm{a}} \pm 0,12$ & $0,52^{\mathrm{a}} \pm 0,12$ \\
\hline $\mathrm{C} 22: 4 \omega 6$ & $0,99^{\mathrm{a}} \pm 0,44$ & $0,39^{a} \pm 0,63$ & $0,47^{\mathrm{a}} \pm 0,54$ & $0,92^{\mathrm{a}} \pm 0,59$ \\
\hline$(\mathrm{DHA})(\mathrm{C} 22: 6 \omega 3)$ & $0,18^{a} \pm 0,02$ & $0,18^{a} \pm 0,03$ & $0,16^{a} \pm 0,03$ & $0,20^{a} \pm 0,03$ \\
\hline$A G S^{1}$ & 38,00 & 41,61 & 38,76 & 39,78 \\
\hline $\mathrm{AGM}^{2}$ & 28,69 & 29,32 & 30,83 & 27,17 \\
\hline $\mathrm{AGP}^{3}$ & 31,68 & 26,63 & 28,27 & 29,58 \\
\hline AGP/AGS $^{4}$ & 0,83 & 0,64 & 0,72 & 0,74 \\
\hline Total $\omega 3$ & 5,73 & 5,52 & 5,67 & 5,59 \\
\hline Total $\omega 6$ & 25,95 & 21,11 & 22,6 & 23,99 \\
\hline
\end{tabular}

Médias seguidas da mesma letra são estatisticamente iguais entre si pelo teste- $t$ (Student) ao nivel de $5 \%$ de probabilidade $(\mathrm{p}<0,05)$, (nas linhas, letras minüsculas são para diferenciar os fatores sexo e método de abate).

Somatório das porcentagens médias de áreas de pico dos AG saturados.

Somatório das porcentagens médias de áreas de pico dos AG monoinsaturados.

Somatório das porcentagens médias de áreas de pico dos AG poliinsaturados.

Relação entre o total de AG poliinsaturados e o total de AG saturados.

Os valores médios de AG, em ordem decrescente, foram: a) saturados (AGS): C16:0 (29,57\%), C18:0 (6,57\%) 
e C14:0 (3,64\%); b) monoinsaturados (AGM): C18:1 109

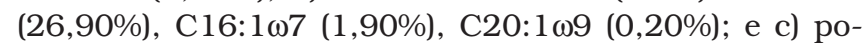

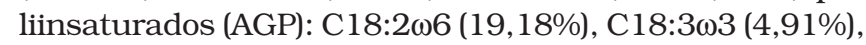

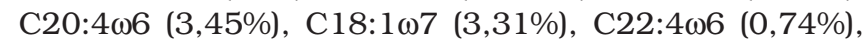

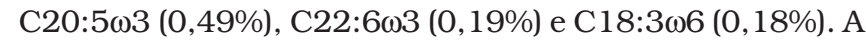
relação entre AGP e AGS foi de 0,82; as médias do total de AG $\omega 6$ e $\omega 3$ foram $23,55 \%$ e 5,59\%, respectivamente; e a relação $\omega 6 / \omega 3$ foi de 4,21 (Tabela 2).

A análise de variância não detectou diferenças nos teores de C14:0 para os fatores sexo e MA no músculo SM e, estes percentuais variaram de 3,15 a 4,34\% (média de 3,64\%). Em capivaras, são relatadas médias de $1,46 \%$ (lombo) e de 1,29\% (paleta) [19, 33]. Em bovinos e ovinos foram citados valores de 3,76 a $5,40 \%$ [6, 28]. Em relação às espécies de caça (zebras, kongoni, oryx, catetos, renas, cervos e avestruzes), foram reportados teores do C14:0 de 0,50-6,30\% [13, 18, 20, 25, 38].

DENKE \& GRUNDY [9] e GRANDE [15] relataram que AG com cadeias de 4 a 10 átomos de carbono não elevam o colesterol sérico. A ingestão de altas concentrações de AGS de cadeia longa aumenta o colesterol sérico [16], entretanto, o C18:0 (AG neutro) é rapidamente convertido a ácido oléico pelo organismo após sua ingestão e não afeta o colesterol plasmático [3].

Foram encontradas diferenças $(\mathrm{p}<0,05)$ nos teores de C16:0 entre os métodos de abate, sendo que o MT apresentou percentual mais elevado $(31,80 \%)$ do que o $\mathrm{MH}(27,34 \%)$. O C16:0 foi o AG encontrado em maior quantidade (média de 29,57\%). Esse é o principal AG responsável pela elevação do colesterol sérico [26]. Em lombo e pernil de capivaras, são relatados valores de C16:0 de 16,38 e 13,68\%, respectivamente [19, 33]. Os valores de AG palmítico encontrados são semelhantes aos valores reportados para novilhos Wagyu $(30,80 \%)$; bovinos nelores $(24,80 \%)$; perus $(30,00 \%)$; zebras, kongoni e oryx $(32,60 ; 27,10$ e $28,10 \%$, respectivamente) $[4,6,25,26]$. Entretanto, são reportadas médias de C16:0 de 12,60 a $26,70 \%$ para ovinos; caprinos; frangos; catetos; avestruzes; cervos e renas [13, 18, 20, 28, 29, 31, 34, 38]. Comparando as médias de C16:0 do presente trabalho com as médias de outras espécies, verificou-se que esses teores apresentaram-se bastante elevados, assemelhando-se apenas aos teores encontrados em bovinos, perus e algumas espécies exóticas.

A análise de variância detectou diferenças $(\mathrm{p}<0,05)$ para os fatores MA e sexo sobre os teores de C18:0. O $\mathrm{MH}$ apresentou médias superiores $(7,33 \%)$ em relação ao MT (5,80\%), enquanto que as $\mathrm{F}$ apresentaram valores superiores $(7,53 \%)$ aos dos $\mathrm{M}(5,60 \%)$. Os valores de AG esteárico no presente trabalho apresentaram média de $6,57 \%$. Em capivaras, são citados valores de 11,13 e $6,13 \%$ para o lombo e paleta, respectivamente [19, 33]. Entretanto, foram encontradas médias de 9,90 a 58,10\% em ovinos; caprinos; novilhos Wagyu e bovinos Nelore; catetos; renas e cervos; zebras, kongoni e oryx e avestruzes $[4,6,13,18,20,25,26,28,29,31,34$, 38]. Em relação aos teores de C18:0 encontrados em capivaras e outras espécies, verifica-se que as médias obtidas são semelhantes às médias citadas em paleta de capivaras e inferiores aos teores de bovinos, ovinos, caprinos, catetos e outras espécies exóticas.

Os percentuais das áreas de pico dos AGS totalizaram 39,54\%. Em capivaras, são relatados valores de 40,94 e 43,70\% [19,33]. Em relação ao total de AGS encontrados em ovinos, caprinos, perus e bovinos, são relatados valores de 42,19 a 55,07\% [6, 26, 28, 29, 31]. Em espécies de caça, foram reportados valores de AGS de 25,40 a $45,60 \%$ em renas, zebras, emas e avestruzes [18, 25, 34, 38]. Os teores de AGS nas espécies domésticas foram superiores aos teores observados em capivaras neste trabalho, os quais foram superiores aos valores citados em outras caças.

A análise de variância não detectou diferença para

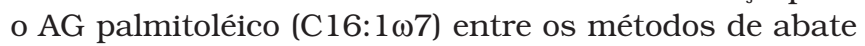
$\mathrm{MH}$ e MT. Por outro lado, houve diferença $(\mathrm{p}<0,05)$ entre os teores de $\mathrm{M}(2,54 \%)$ e $\mathrm{F}(1,24 \%)$. Os valores de AG palmitoléico encontrados variaram de 1,09 a 2,63\%. Em paletas de capivaras, são relatadas médias de 1,12 a 1,56\% [33], e em lombos, médias de 0,54-1,09\% [19]. São relatadas médias de C16: $1 \omega 7$ de 1,62-7,20\% em bovinos; caprinos; perus; frangos; catetos e avestruzes $[6,13,18,25,26,34]$.

A análise de variância não detectou efeito para os

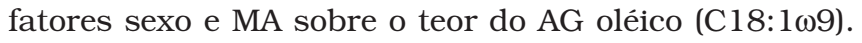
Essas porcentagens variaram de 24,24 a 29,63\% (média de $27,87 \%$ ). Em paletas e lombos de capivaras, foram encontrados valores de 20,05 e 11,66\%, respectivamente [19, 33]. O AG oléico participa de processos fisiológicos e apresenta efeito hipocolesterolêmico [3, 16]. Além disso, o C18:1 19 é utilizado no organismo como fonte preferencial de energia metabolizável no crescimento rápido. Os valores de C18:1 $\omega 9$ encontrados foram inferiores aos valores relatados em ovinos $(30,73-$ $45,19 \%)$; caprinos $(42,43 \%)$; em novilhos Wagyu $(42,00 \%)$ e em bovinos $(37,20 \%)[6,26,28,31]$. Em aves, foram encontradas médias de 35,50\% em perus [26] e 39,80\% em frangos [34]. Em espécies de caça, foram relatados valores superiores em catetos $(28,37-37,77 \%)$; emas $(29,50 \%)$ e avestruzes $(33,25 \%)[13,18,34]$. Comparando as porcentagens de C18: $1 \omega 9$ obtidas no presente trabalho com as encontradas em espécies domésticas, verifica-se que a carne de capivara apresenta teores mais reduzidos desse $\mathrm{AG}$. Em relação às espécies de caça, os teores de C18:1 19 foram superiores aos encontrados em cervos (24,51\%) [20].

O total da área de picos de AGM foi de 29,0\%. Em capivaras, são reportados teores de 11,96 a 15,61\%de AGM em lombo [19] e de $25,05 \%$ em paleta de machos [33], inferiores aos obtidos no presente trabalho. Em espécies domésticas, foram relatados valores de AGM de 31,37 a $48,60 \%$ em ovinos, caprinos, novilhos, frangos e perus [6, 26, 27, 29, 31, 34]. Em espécies de caça, foram reportados percentuais de AGM de 17,30-41,80\% em renas, zebras, oryx, emas e avestruzes [25, 26, 28, 34].

A análise de variância de C18:1 $1 \omega 7, \mathrm{C} 18: 2 \omega 6$,

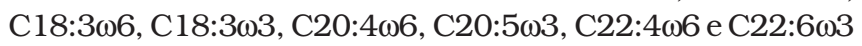
em SM de capivaras não detectou influência dos fatores

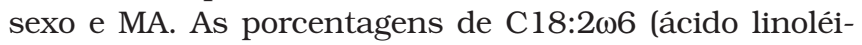


co) encontradas variaram de 15,35 a 22,57\% (média de 19,19\%). Em lombo e pernil de capivaras são descritos valores de 18,78\% e 15,11\%, respectivamente [19, 33]. Em ovinos, caprinos, bovinos, frangos e perus são relatados valores de 1,90 a 13,50\% [4, 6, 26, 28, 29, 34] e em catetos, renas, cervos, emas, zebras e avestruzes, médias de 14,10 a 30,40\% [13, 20, 25, 34, 38]. A carne de capivara no presente estudo apresentou médias superiores em relação às espécies domésticas citadas.

As porcentagens de C18:3 $\omega 6$ (ácido $\gamma$-linolênico) variaram de 0,16 a $0,19 \%$, com média de $0,18 \%$. Em ovinos são relatadas médias de 0,21 a $0,69 \%$ [28, 31]. Os valores médios de C18:3 16 em músculo SM de capivara foram inferiores aos valores citados para ovinos.

As porcentagens de C18:3 13 (ácido $\alpha$-linolênico) variaram de 4,34 a 5,53\% (média de 4,97\%). Em lombos e paletas de capivaras, são relatados valores de 0,24 a $0,47 \%$ e de $4,23 \%$, respectivamente $[19,33]$. Os teores desse AG encontrados no presente trabalho foram superiores aos relatados para caprinos e ovinos [29, 31]. Em relação às carnes de espécies silvestres e exóticas, foram relatados teores superiores de C18:3 03 em cer$\operatorname{vos}(5,50 \%)$, zebras $(18,10 \%)$ e avestruzes $(5,68 \%)$ [ 18 , $20,25]$. Por outro lado, foram citados teores inferiores em catetos $(0,26$ a $0,67 \%)$ e emas $(4,60 \%)$ [13, 34]. O teor médio encontrado em pernil de capivara no presente estudo foi superior aos encontrados em lombo e paleta de capivaras. Em relação às espécies domésticas e de caça, os teores médios de C18:3 13 encontrados no presente trabalho são superiores aos reportados para ovinos, caprinos, frangos, catetos e emas.

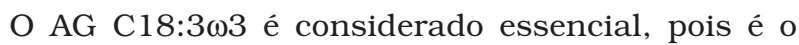
precursor para a síntese de muitos AGP, como os áci-

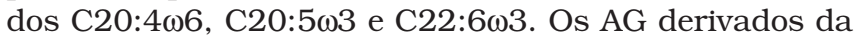
ação de enzimas (cicloxigenases e lipoxigenases) são os eicosanóides, substâncias moduladoras de funções vitais, participando de processos secretórios, digestivos, reprodutivos, imunológicos e circulatórios [36].

As porcentagens de C20:4 66 encontradas variaram de 2,15 a $4,78 \%$ (média de $3,45 \%$ ). Em capivaras, são relatados valores de $6,66 \%$ no lombo e de $1,70 \%$ em pernil [19, 33]. Os valores desse AG foram superiores às médias relatadas para bovinos $(0,50 \%)$; ovinos $(1,14$ e $2,82 \%)$; perus $(0,90 \%)$ e frangos $(0,70 \%)[4,26,28$,

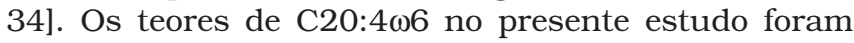
inferiores aos relatados para avestruzes (5,30 e 5,81\%); emas $(5,00 \%)$ e cervos $(8,50 \%)[18,20,34]$. A porcentagem de C20:4 16 em capivaras mostrou-se superior aos valores citados para bovinos, ovinos, caprinos, perus e frangos. Isso revela um aspecto favorável ao consumo da carne de capivara, pois esse é considerado um AG

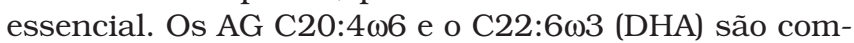
ponentes estruturais predominantes da substância cinzenta do cérebro e da retina e, dessa forma, devem fazer parte da dieta da mãe para estarem disponiveis ao feto (tecido placentário) e ao recém-nascido (amamentação) [36].

As porcentagens de EPA variaram de 0,31 a 0,64\% (média de 0,48\%). Em lombo e pernil de capivaras, são citadas médias de $1,60 \%$ e de $0,79 \%$ [19, 33]. Os teores de EPA observados no presente trabalho foram superiores aos relatados para bovinos $(0,10 \%)$ e para frangos $(0,40 \%)$ [4] e inferiores aos teores citados para emas $(0,80 \%)$, avestruzes $(0,56 \%)$ e renas $(2,70 \%)[18,34,38]$. Comparando os dados obtidos no presente experimento com os encontrados na literatura, verifica-se que o teor de EPA em pernil de capivaras foi superior aos dados relatados para bovinos e frangos, porém foram inferiores aos dados de literaturas para emas, avestruzes e renas.

O total de AGP foi de 29,04\%. Em lombos de capivaras são relatados valores totais de AGP de 25,36 a $30,13 \%$ e no pernil, de $35,41 \%$ [19, 33]. Em ovinos, caprinos e bovinos são relatados valores de 5,36 a 12,54\%, [4, 28, 29]. Em espécies silvestres e exóticas são reportados valores de $0,80 \%$ em emas e de $23,78 \%$ em avestruzes [18, 34]. Comparando os valores observados de AGP no presente trabalho com os citados para outras espécies, observa-se que a carne de capivara apresenta um percentual de AGP mais elevado. Considerando os aspectos tecnológicos, quanto maior o grau de insaturação da gordura das carnes, mais rápido acontece a oxidação e menor é a vida-de-prateleira da carne [27]. Entretanto, com relação aos aspectos de saúde, os AGP ingeridos na dieta humana são responsáveis pela redução nos níveis de colesterol séricos.

O teor médio de AG da família $\omega 3$ foi de 5,63\%. Foram relatados teores de $\omega 3$ de 0,80 a 3,30\% para lombo e paleta de capivaras, bovinos, emas e avestruzes [4, $18,19,26,33,34]$. Os AG $\omega 3$ são essenciais ao desenvolvimento das células nervosas do feto durante a gestação [36].

O teor médio de AG da família $\omega 6$ encontrado foi de 23,41\%. Ainda em capivaras, JARDIM [19] encontrou um total de AG $\omega 6$ de 25,50\%, e SALDANHA [33], de $16,81 \%$. Em bovinos e ovinos, foram encontrados percentuais de $11,06 \%$ e $3,64 \%$ de AG $\omega 6$ [4, 31]. Com isso, é possivel afirmar que a carne de capivaras apresenta teores de $\omega 6$ superiores aos de bovinos e ovinos.

$\mathrm{O}$ efeito biológico dos AG essenciais depende da razão dos AG das famílias $\omega 6 / \omega 3$, presentes nos fosfolipídios de membranas e alguns autores consideram que a razão $\omega 6 / \omega 3$ ideal é a de 10-11:1 [36]. Entretanto, a The World Health Organization [10] recomenda razões de AGP $\omega 6 / \omega 3$ entre 3:1 e 4:1. No presente trabalho, a proporção de AGP $\omega 6 / \omega 3$ foi de $4: 1$, considerada nutricionalmente adequada.

\section{3 - Teor de colesterol}

Os teores médios de colesterol variaram de 23,33 a $33,22 \mathrm{mg} / 100 \mathrm{~g}$, com média geral de $28,11 \mathrm{mg} / 100 \mathrm{~g}$. Em capivaras, são citados valores de 23,30 a 44,00mg/100g $[19,22,33]$. Os teores de colesterol (mg/100g) relatados para bovinos $(51,00)$, ovinos (de 62,03-76,90), frangos $(36,30)$, perus $(70,00)$, codorna $(79,00)$, perdiz $(80,00)$ e faisão $(62,00)$ foram superiores aos teores encontrados no presente trabalho $[5,11,26,28,31,34]$. Normalmente, os animais silvestres apresentam teores de 
colesterol inferiores aos encontrados em carnes de espécies convencionais. São relatados valores (mg/100g) de colesterol de: 36,99 em catetos fêmeas e 48,78 em catetos machos [13]; de 63,50 em jacaré-do-Pantanal [32]; de 33,80 e 57,00 em avestruzes [26]; e de 59,00 em emas [34]. Observou-se que o músculo SM de capivaras apresentou médias inferiores a todas as outras espécies domésticas e de caça.

\section{4 - CONCLUSÕES}

- Os teores de umidade, proteína e cinzas no músculo LD, e de colesterol no músculo SM, não foram influenciados pelos efeitos dos métodos de abate e do sexo.

- As capivaras machos apresentaram teores de lipídios totais mais elevados $(1,75 \%)$ do que as capivaras fêmeas $(0,98)$ no músculo SM.

- Os fatores método de abate e sexo não influen-

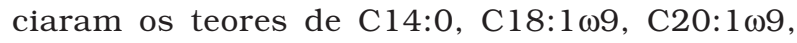
$\mathrm{C} 18: 1 \omega 7, \mathrm{C} 18: 2 \omega 6, \mathrm{C} 18: 3 \omega 6, \mathrm{C} 18: 3 \omega 3, \mathrm{C} 20: 4 \omega 6$,

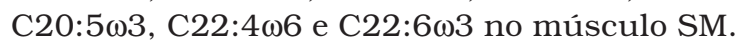

\section{5 - REFERÊNCIAS BIBLIOGRÁFICAS}

[1] ASSOCIATION OF OFFICIAL ANALYTICAL CHEMISTS. Official Methods of Analysis of the Association of Official Analytical Chemists. 15. ed. Arlington, 1990.

[2] BOHAC, C. E.; RHEE, K. S.; CROSS, H. R.; ONO, K. Assesment of methodologies for colorimetric cholesterol assay of meats. J. Food Sci., Chicago, v. 53, n. 6, p. 1642-1645, Nov./Dec. 1988.

[3] BONANOME A. M. D.; GRUNDY S. M. Effect of dietary stearic acid on plasma cholesterol and lipoprotein levels. New England J. Medicine, Boston, v. 318, n. 19, p. 1244-1247, May 1988.

[4] BRAGAGNOLO, N. Fatores que influenciam o nível de colesterol, lipídios totais e composição de ácidos graxos em camarão e carne. 1997. 123 p. Tese (Doutorado em Ciência de Alimentos) - Universidade de Campinas, Campinas, SP.

[5] BRAGAGNOLO, N.; RODRIGUEZ-AMAYA, D. B. Teores de Colesterol em Carne Suína e Bovina e Efeito do Cozimento. Ciênc. Tecnol. Aliment., Campinas, v. 15, n. 1, p. 11-17, jan./jun. 1995.

[6] CALleS, J. A. E.; GASKINS, C. T.; BUSBOOM, J. R.; DUCKETT, S. K.; CRONRATH, J. D.; REEVES, J. J. Sire variation in fatty acid composition of crossbred Wagyu steers and heifers. Meat Science, Oxford, v. 56, n. 1, p. 23-29, Sept. 2000.

[7] DAWOOD, A. A.; ALKANHAL, M. A. Nutrient composition of Najdi-Camel meat. Meat Science, Oxford, v. 39, n. 1, p. 71-78, 1995.

[8] DELAZARI, J. A. Desempenho reprodutivo, concentração de progesterona e metabólitos lipídicos no pós parto de vacas mestiças holandesas-zebu submetidas a dietas hiperlipidêmicas. 1996. 74 p. Dissertação (Mestrado) - Universidade Federal de Viçosa, Viçosa, MG.

[9] DENKE, M. A.; GRUNDY, S. M. Comparison on effects of lauric acid and palmitic acid on plasma lipids. Am. J. Clin. Nutrition, Bethesda, v. 56, n. 5, p. 895-898, Nov. 1992.
[10] FAO/WHO. Report of a joint expert consulation: fats and oils in human nutrition. Food and Nutrition Paper, Rome, v. 57, n. 1, p. 49-55, 1994.

[11] FIALHO, N. A. V.; BRAGAGNOLO, N. Lipídios totais, colesterol e composição de ácidos graxos em carnes de codorna, perdiz e faisão. In: CONGRESSO BRASILEIRO DE CIÊNCIA E TECNOLOGIA DE ALIMENTOS, 17., 2000, Fortaleza, CE. Anais... Fortaleza: CBCTA, 2000.

[12] FOLCH, J.; LEES, M.; SLOANE-STANLEY, G. H. A simple method for the isolation and putification of total lipids from animal tissue. J. Biol. Chem., Baltimore, v. 226, n. 1, p. 497-509, May. 1957.

[13] FREIRE, K. R.; BESERRA, F. J.; PINHEIRO, M. J. P.; NOGUEIRA, C. M.; CARRARO, F. Efeito do sexo e da castração no perfil de ácidos graxos e teor de colesterol da carne de cateto (Tayassu tajacu). In: CONGRESSO BRASILEIRO DE CIÊNCIA E TECNOLOGIA DE ALIMENTOS, 17., 2000, Fortaleza, CE. Anais... Fortaleza: CBCTA, 2000.

[14] GAONA, J. L. T. La carne del chigüiro como alimento. Temas de Orientacion Agropecuaria, Bogotá, v. 9, n. 99, p. 69-75, 1987.

[15] GRANDE, F. Dog serum lipid responses to dietary fats differing in the chain lenght of the satured fatty acids. J. Nutrition, Bethesda, v. 76, n. 3, p. 255-264, Mar. 1962.

[16] GRUNDY, S. M. Comparison of monounsaturated fatty acids and carbohydrates for lowering plasma cholesterol. New England J. Medicine, Boston, v. 314, n. 7, p. 745-748, july 1986.

[17] HARTMAN, L.; LAGO, R. C. Rapid preparation of fatty acid methyl esters. Laboratory Practice, London, v.494, n. 22, p. 475-476, Jul., 1973.

[18] HORBAÑCZUK, J.; SALES, J.; CELEDA, T.; KONECKA, A.; ZIÊBA, G.; KAWKA, P. Cholesterol content and fatty acid composition of ostrich meat as influenced by subspecies. Meat Science, Oxford, v. 50, n. 3, p. 385-388, Nov. 1998.

[19] JARDIM, N. S. Sexo e diferentes pesos ao abate na qualidade da carne de capivara (Hydrochaeris hydrochaeris L. 1766). 2001. 119 p. Dissertação (Mestrado em Ciência de Alimentos) - Universidade Federal de Lavras, Lavras, MG.

[20] MANLEY, T. R.; FORSS, D. A. Fatty acids of meat lipids from young red deer (Cervus elaphus). J. Sci. Food Agric., London, v. 30, n. 9, p. 927-931, Sept. 1979.

[21] MARCHIORI, A. F. Composição e propriedades físicoquímicas da carne de javali e de suíno comercial. 2001. 71 p. Dissertação (Mestrado em Tecnologia de Alimentos) - Universidade de Campinas, Campinas, SP.

[22] MIGUEL, G. Z. Caracterização da carcaça e da carne de capivaras (Hydrochaeris hydrochaeris L. 1766) em idade adulta. 2002. 107 p. Dissertação (Mestrado em Ciência de Alimentos) - Universidade Federal de Lavras, Lavras, MG.

[23] MONTEIRO, E. M.; RÜBENSAM, J., PIRES, G. Avaliação de parâmetros de qualidade da carcaça e da carne de ovinos. In: CONGRESSO BRASILEIRO DE CIÊNCIA E TECNOLOGIA DE CARNES, 1., 2001. São Pedro, SP. Anais... São Pedro: CTC/ITAL, 2001.

[24] NORKUS, E. A.; SOUZA, H. B. A., SOUZA, P. A.; OBA, A.; KODAWARA, L. M.; LEONEL, F. R.; PELICANO, E. R. L. Avaliação da qualidade física e química da carne de frangos abatidos com diferentes idades. In: CONGRESSO BRASILEIRO DE CIÊNCIA E TECNOLOGIA DE CARNES, 1., 2001, São Pedro, SP. Anais... São Pedro: CTC/ITAL, 2001. 
[25] ONYANGO, C. A.; IZUMIMOTO, M.; KUTIMA, P. M. Comparison of some physical and chemical properties of selected game meats. Meat Science, Oxford, v. 49, n. 1, p. 117-125, May 1998.

[26] PALEARI, M. A.; CAMISASCA, S.; BERETTA, G.; RENAN, P.; CORISCO, P.; BERTOLO, G.; CRIVELLI, G. Ostrich meat physico chemical characteristics and comparison with turkey and bovine meat. Meat Science, Oxford, v. 48, n. 3/4, p. 205-210, Mar./Apr. 1998.

[27] PARDI, M. C.; SANTOS, I. F.; SOUZA, E. R.; PARDI, $\mathrm{H}$. S. Ciência, higiene e tecnologia da carne: tecnologia da sua obtenção e transformação. Goiânia: Universidade de Goiás, 1993. v. 1, 586 p.

[28] PRADO, O. V. Gualidade de carne de cordeiros Santa Inês e Bergamácia abatidos em diferentes pesos. 1999. 109 p. Dissertação (Mestrado em Zootecnia) Universidade Federal de Lavras, Lavras, MG.

[29] RHEE, K. S.; WALDRON, D. F.; ZIPRIN, Y. A.; RHEE, K. C. Fatty acid composition of goat diets vc intramuscular fat. Meat Science, Oxford, v. 54, n. 4, p. 313-318, Apr. 2000.

[30] ROÇA, R. O.; VEIGA, N.; SILVA NETO, P. B.; CINTI, R. Desenvolvimento de produtos curados e defumados com carne de capivara (Hydrochoerus hydrochaeris). In: CONGRESSO BRASILEIRO DE CIÊNCIA E TECNOLOGIA DE ALIMENTOS, 15., 1996, Poços de Caldas. Anais... Poços de Caldas: SBCTA, 1996.

[31] ROWE, A.; MACEDO, F. A. F.; VISENTAINER, J. V.; SOUZA, N. E.; MATSUSHITA, M. Muscle composition and fatty acid profile in lambs fattened in drylot or pasture. Meat Science, Oxford, v. 51, n. 4, p. 283388, Apr. 1999.

[32] ROMANELli, P. F.; FELÍcio, P. E. Jacaré do Pantanal (Caiman Crocodilus yacare): rendimentos de abate e composição da carne. Hig. Alim., São Paulo, yv. 13, n. 60, p. 11-15, mar. 1999.

[33] SALDANHA, T. Determinação da composição centesimal nos diferentes cortes da carne de capivara
(Hydrochoerus hydrochaeris). 2000. 105 p. Dissertação (Mestrado em Ciência e Tecnologia de Alimentos) - Universidade Federal Rural do Rio de Janeiro, Rio de Janeiro.

[34] SAlES, J.; NAVARRO, J. L.; MARTElla, M. B.; LIZURUME, M. E.; MANERO, A.; BELLIS, L.; GARCIA, P. T. Cholesterol content and fatty acid composition of rhea meat. Meat Science, Oxford, v. 53 , n. 2, p. 7375, Oct. 1999.

[35] SAS INSTITUTE. SAS user's guide: statistics. 5. ed. Cary, North Carolina, 1985. 956 p.

[36] SIMOPOULOS, A. P. Summary of the nato advanced research workshop on dietary w-3 and w- 6 fatty acids: biological effects and nutritional essentiality. Am. Inst. Nutrition, Philadelphia, v. 22, p. 521-526, 1991.

[37] SINCLAIR, A. J.; O'DEA, K. Fats in Human diets through history: is the western diet out of step? In: WOOD, J. D.; FISHER, A. V. Reducing fat in meat animals. London: Elsevier, 1990. p. 1-47.

[38] WIKLUND, E.; PICKOVA, J.; SAMPELS, S.; LUNDSTRÖM, K. Fatty acid composition of M. longissimus lumborum, ultimate muscle $\mathrm{pH}$ values and carcass parameters in reideer (Rangifer tarandus tarandus L) grazed on natural pasture or fed a commercial feed mixture. Meat Science, Oxford, v. 58, n. 3, p. 293-298, July 2001.

[39] ZOMBORSZKY, Z.; SZENTMIHÁLYI, G.; SARUDI, I.; HORN, P.; SZABÓ, C. S. Nutrient composition of muscles in deer and boar. J. Food Sci., Chicago, v. 61, n. 3, p. 625-626, May/June 1996.

\section{6 - AGRADECIMENTOS}

Os autores agradecem: ao CNPq pela concessão de recursos para o desenvolvimento do projeto; à Universidade Federal de Lavras pela concessão de bolsa de trabalho à aluna Josye O. e Vieira; e, à Empresa PróFauna Assessoria e Comércio Ltda pela doação de amostras e apoio logístico. 